INTERNATIONAL BULLETIN

OF

BACTERIOLOGICAL NOMENCLATURE

AND

T AXONOM Y

Volume 10

July 15, 1960

No. 3

\title{
FLAGELLATION IN SIX SPECIES \\ OF SPIRILLUM - A CORRECTION ${ }^{1}$
}

\author{
Marion A. Williams \\ Harvard University \\ The Biological Laboratories \\ Cambridge, Massachusetts
}

Williams and Rittenberg (1957) described six species of the genus Spirillum Ehrenberg as having a single flagellum at each pole in flagellar-stain preparations. Five of the

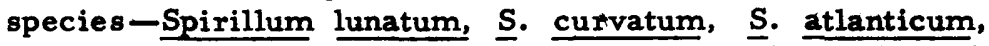
s. beijerinckii and s. anulus -were new species; the sixth

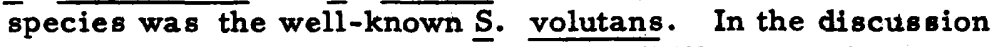
of flagellation in species of Spirillum Williams and Rittenberg mention the fact that when Leifson's (1951) method of flagellar staining was used that the so-called ' single flagellated' species often showed multiple flagella. Inasmuch as variable results were obtained by routine flagellar stain methods, these authors recommended a survey of flagellation in species of Spirillumby means of the electron microscope to resolve this difficulty.

Such electron microscope photographs have been made and it was found that all six species, mentioned above, have multiple flagella. In some instances, even in electron microscope photographs, the flagella are tightly agglutinated to each other, and in flagellar-stain preparations would probably appear as a single flagellum. Such a fascicle of flagella is shown in S. atlanticum in figure 1. In other preparations, the flagella are separated as is shown in figure 2 of S. volutans.

Due to the fact that the six species of Spirillum, described by Williams and Rittenberg (1957) as having a single

\footnotetext{
'This investization was supported by a research fellowship (EF-9726) from the National Institute of Allergy and Infectious Diseases. U.S. Public Health Service.
}

(Page 193) 
Page 194

INTERNATIONAL BULLETIN

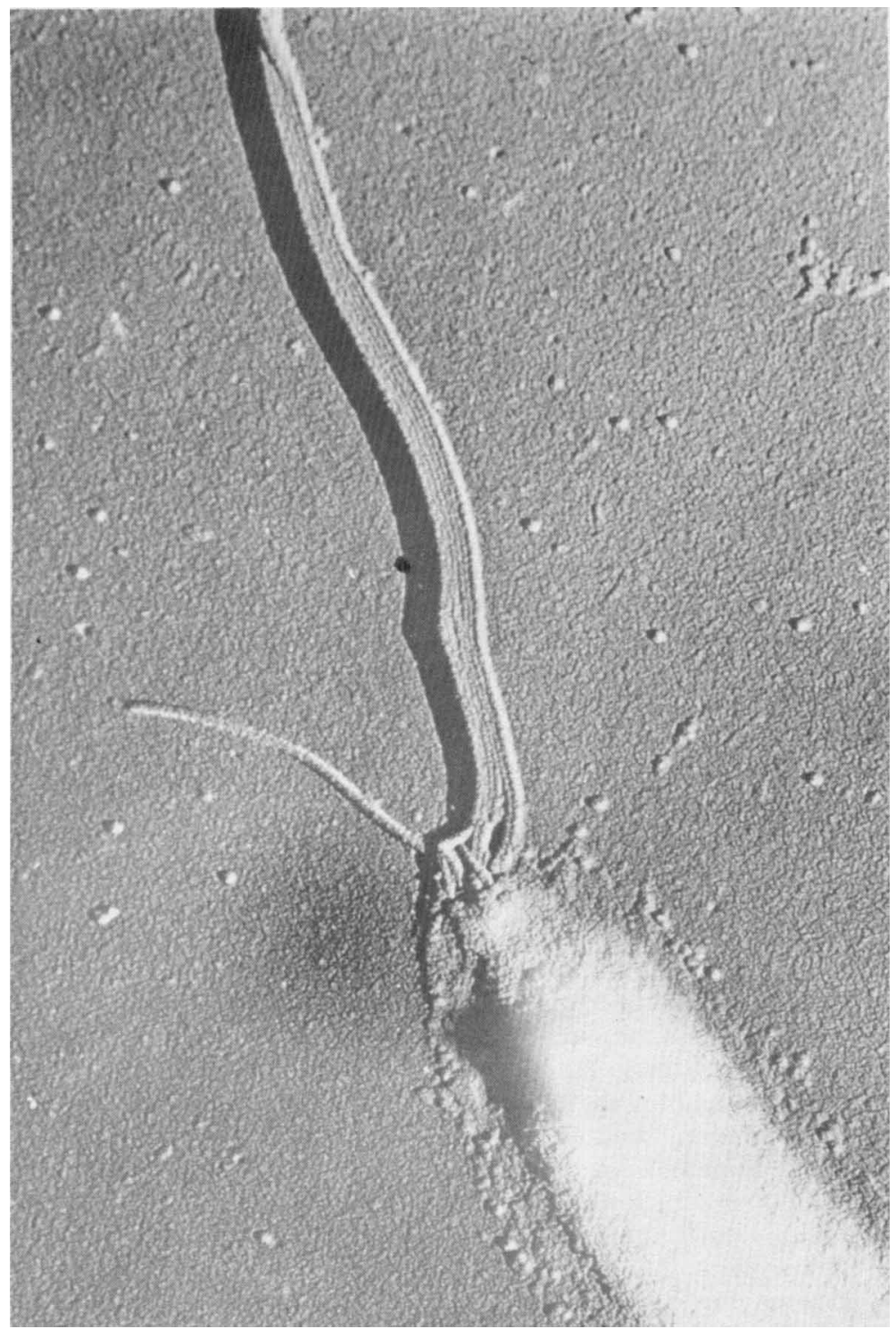

Figure 1. Electron microscope photograph of

S. atlanticum showing multiple flagella which are agglutinated together. Magnification 48, $000 \mathrm{X}$. 
BACTERIOLOGICAL NOMENCLATURE AND TAXONOMY

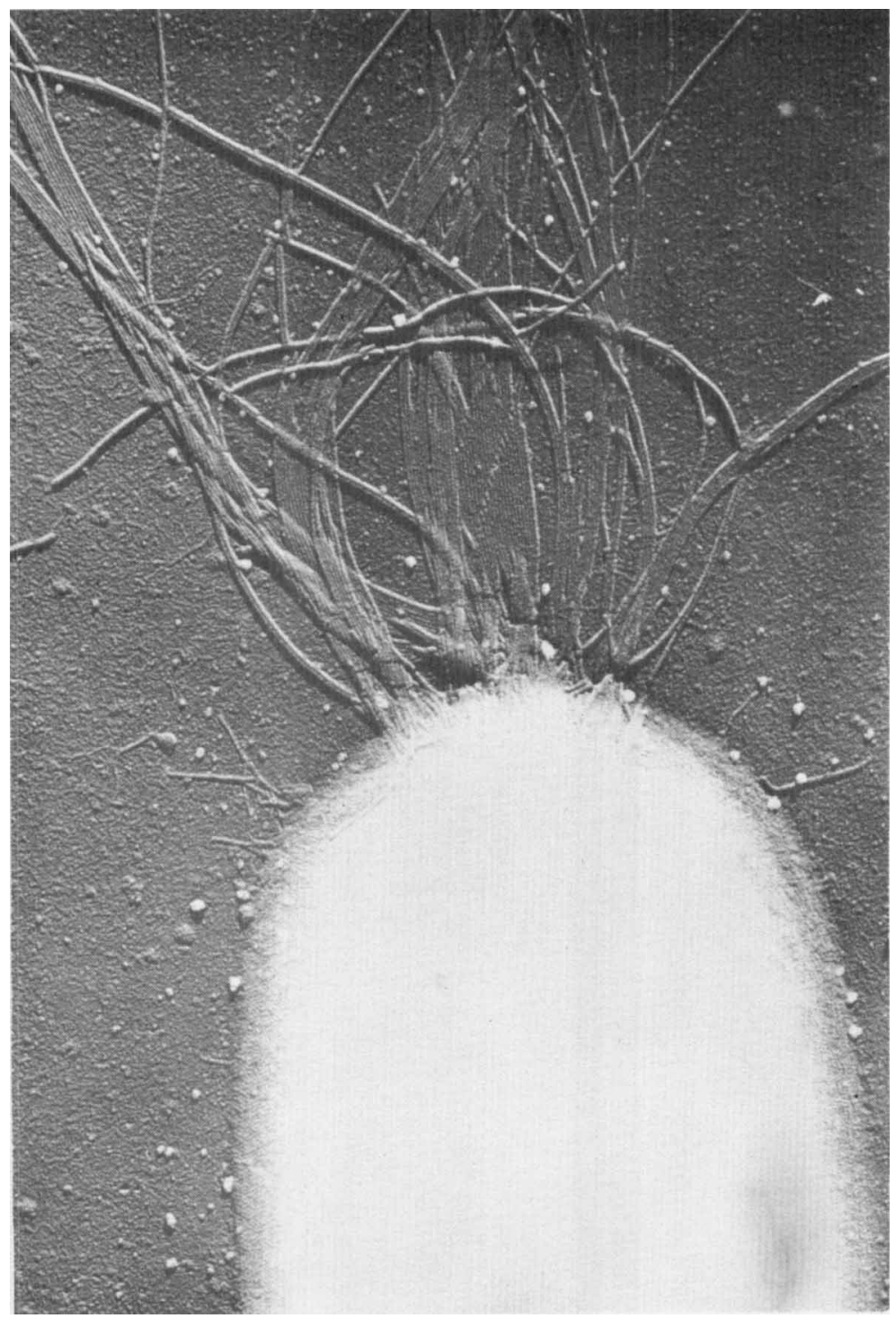

Figure 2. Electron microscope photograph of S. volutans showing multiple flagella. Magnification 33, $500 \mathrm{X}$. 
Page 196

INTERNATIONAL BULLETIN

flagellum at each pole, have been shown to possess multiple flagella, the description of these species should be emended to read: "motile by tufts of bipolar flagella".

REFERENCES

1. Leifson, E. 1951. Staining, shape, and arrangement of bacterial flagella. Jour. Bact. 62: 377-389.

2. Williams, M.A. and S.C. Rittenberg. 1957. A taxonomic study of the genus Spirillum Ehrenberg.

Intern. Bull. Bact. Nomen. and Taxon. 7: 49-104. 